\title{
Comparison of the central venous pressure from internal jugular vein and the pressure measured from the peripherally inserted antecubital central catheter (PICCP) in liver transplantation recipients
}

\author{
Jung-Yeon Yun ${ }^{1}$, So-Hee Park ${ }^{2}$, Dae-Soon Cho ${ }^{1}$, Hae-Jeung Jeung ${ }^{1}$, Soon-Ae Lee ${ }^{1}$, and So Jin Seo ${ }^{3}$
}

Departments of ${ }^{1}$ Anesthesiology and Pain Medicine, ${ }^{2}$ Cancer Registration and Biostatistics Branch, Research Institute and Hospital, National Cancer Center, Goyang, ${ }^{3}$ Department of Anesthesiology and Pain Medicine, Seoul National University Hospital, Seoul, Korea

Background: Unlike its use during stable conditions, central venous pressure (CVP) monitoring from a peripherally inserted central venous catheter (PICC) has not often been used in surgeries with significant hemodynamic alterations. The aim of this study was to evaluate the feasibility of measuring PICC pressure (PICCP) as an alternative to measuring centrally inserted central catheter pressure (CICCP) in adult liver transplantation (LT) patients.

Methods: We measured PICCP and CICCP simultaneously during each main surgical period in adult LT. Statistical analysis was performed using simple linear regression analysis to observe whether changes in PICCP paralleled by simultaneous changes in CICCP. Correlation analysis and Bland-Altman analysis were used to determine the degree of agreement between the two devices. Differences were considered statistically significant when P values were less than 0.05 .

Results: A total of 1342 data pairs were collected from 35 patients. The PICCPs and CICCPs were highly correlated overall $(\mathrm{r}=0.970, \mathrm{P}<0.001)$ as well as at each period measured. The differences among each period were not clinically significant $(0.33 \mathrm{mmHg}$ for pre-anhepatic, $0.32 \mathrm{mmHg}$ for anhepatic, $-0.15 \mathrm{mmHg}$ for reperfusion, and $-0.10 \mathrm{mmHg}$ for neohepatic periods). The overall mean difference was $0.14 \mathrm{mmHg}$ (95\% confidence interval: $0.09-$ 0.19 ) and PICCP tended to give a higher reading by between 0.09 and $0.19 \mathrm{mmHg}$ overall. The limit of agreement was -1.74 to 2.02 overall.

Conclusions: These findings suggest that PICCP can be a reasonable alternative to CICCP in situations of dynamic systemic compliance and preload, as well as under stable hemodynamic conditions. (Korean J Anesthesiol 2011; 61: 281-287)

Key Words: CVP, Liver transplantation, Peripherally inserted central catheter pressure.

Received: January 25, 2011. Revised: 1st, March 20, 2011; 2nd, April 22, 2011. Accepted: April 26, 2011.

Corresponding author: Jung-Yeon Yun, M.D., Department of Anesthesiology and Pain Medicine, Research Institute and Hospital, National Cancer Center, 323, Ilsan-ro, Ilsandong-gu, Goyang 410-769, Korea. Tel: 82-31-920-1466, Fax: 82-31-920-1463, E-mail: yaeppun@korea.com (c) This is an open-access article distributed under the terms of the Creative Commons Attribution Non-Commercial License (http:// creativecommons.org/licenses/by-nc/3.0/), which permits unrestricted non-commercial use, distribution, and reproduction in any medium, provided the original work is properly cited. 


\section{Introduction}

Trends in central venous pressure (CVP) may be a reasonable surrogate for changes in central volume [1] and valuable information is obtained by examining the waveforms of the CVP tracing [2]. However, the cannulation for a central venous catheter (CVC) can place patients at risk, with fatal complications such as arrhythmia [3], pneumothorax [4], inadvertent arterial puncture [5], hemothorax [6] or cardiac tamponade $[7,8]$.

Because the peripherally inserted central venous catheter (PICC) can be placed without the acute risks associated with direct catheterization of a CVC into the central vessels, it is an attractive alternative to the conventional CVC, or a centrally inserted central catheter (CICC) [9] thus avoiding possible complications associated with direct central vein catheterization.

Although the tip of the PICC is located in the central vascular structure, the monitoring of PICC pressure (PICCP) has not often been used for CVP measurement, owing to the perception that PICCP might be significantly different than CVP measured from a CICC due to its longer length and the resulting higher resistance. Based on laboratory studies with the PICC connected to a constant infusion device [10], PICCP is expected to be higher than CICCP by 3 to $4 \mathrm{mmHg}$. But, when it was measured in 12 patients in the intensive care unit [10], PICCP was only about $1 \mathrm{mmHg}$ higher than CICCP with a pressure infusion device to overcome the natural resistance of the PICC. However, this study was performed in non-surgical patients. There has been only one study which compared CICCP with PICCP in patients undergoing surgeries with large hemodynamic alterations [11]. To reliably use PICCP as an alternative to CICCP during surgeries, it is necessary to study the relationship of PICCP and CICCP in operations with hemodynamic instability.

Liver transplantation (LT) patients undergo extreme hemodynamic fluctuations due to manipulation of the major vascular structures, resulting in large swings in blood volume, systemic vascular resistance and cardiac output [12]. Therefore, we hypothesized that if PICCP can reliably reflect CICCP during each main surgical period of LT (i.e. the preanhepatic, anhepatic, reperfusion and neohepatic periods), PICC can be readily used instead of CICC for CICCP measurements during hemodynamically variable surgeries like LT.

The objective of this study was to determine the degree of agreement between PICCP and CICCP, and whether there are changes in CVP profiles with regard to the different time periods during LT.

\section{Materials and Methods}

The study subjects were adults that had been scheduled for elective liver transplant surgery in our hospital. Informed consent was obtained from all patients in advance and the protocol of the present study was approved by the Institutional Review Board at our institution.

Patients did not receive premedication. General anesthesia was induced with thiopental ( $5 \mathrm{mg} / \mathrm{kg})$ and fentanyl $(1.5 \mu \mathrm{g} /$ $\mathrm{kg})$. Vecuronium $(0.1 \mathrm{mg} / \mathrm{kg})$ was given to facilitate orotracheal intubation with a cuffed tube. Anesthesia was maintained with $1.5-3.0 \%$ sevoflurane or $1-2 \%$ isoflurane in $50 \%$ oxygenmedical air balance, with positive pressure ventilation. Advanced venous access High Flow (AVA-HF, 9-French, 10-cmlong poly-urethane catheter, Edwards Lifesciences, Irvine, CA, USA) and pulmonary artery catheter (PAC, 7-French, 110-cmlong Swan-Ganz poly-urethane catheter, Edward Lifesciences, Irvine, CA, USA) were inserted. A double-lumen, open-ended PICC (16-gauge, 55-cm-long poly-urethane catheter, Arrow International, Reading, PA, USA) was placed through the largest vein around the antecubital area.

After all cannulations and insertions, anterior-posterior chest radiography was checked to confirm the appropriate locations of all catheters. The CVP port of PAC and the PICC tip was confirmed to be located in the lower SVC or slightly into the right atrium. The patient was in the supine position with the arms in $90^{\circ}$ abduction on an arm board during the PICC insertion and throughout the operation.

CICCP and PICCP measurements were taken from the CICC and PICC simultaneously every 10 minutes. In the reperfusion phase, each pressure was measured every minute due to the rapid hemodynamic changes that can occur during this period. At least 6 pairs of data were collected at each main surgical period (i.e. preanhepatic, anhepatic, reperfusion and neohepatic periods). Measurements were recorded at the end of expiration during positive pressure ventilation. Transducers, which use a continuous infusion device with non-heparinized saline at $2 \mathrm{ml} / \mathrm{hr}$, were leveled to the height of the right atrium at the patient's midaxillary line and zeroed to atmospheric pressure. A 16-gauge pressure tubing (Baxter Healthcare, Deerfield, IL, USA) was connected to the CICC, the PICC, and the pressure transducer with a three-way stopcock. The threeway stopcock was turned to place the PICC or CICC in line with the transducer for each measurement. Measurements were taken in rapid succession, with each measurement was taken after the catheter was briefly flushed each time with saline and after the waveform had equilibrated. All pressure measurements were recorded as the digital mean using the Hewlett Packard M1097A monitor (Phillips Medical Systems, Boeblingen, Germany). 
This study was designed to have at least 30 patients based on a sample size calculation to detect the mean difference of $1 \mathrm{mmHg}$ and standard deviation of $1.6 \mathrm{mmHg}$ (equivalent to having an effect size of 0.625 ) at the $5 \%$ significance level and with $90 \%$ statistical power. Data are presented as means \pm standard deviation. Statistical analysis was performed using a simple linear regression model in all patients and for each period of surgery to determine whether changes in PICCP paralleled changes in CICCP. To determine the degree of agreement between the two devices, the difference between the PICCP and the CICCP measurements was plotted against the averages of the two devices (Bland-Altman analysis) [13]. Bias was calculated as the mean of the difference between the simultaneous PICCP and CICCP measurements. The limits of agreement of the bias were defined as the bias $\pm(1.96 \times$ standard deviation). To assess the precision of the estimated limit of agreement, 95\% confidence intervals for the bias were calculated.

A clinical limit of agreement was defined as $\pm 2 \mathrm{mmHg}$

Table 1. Demographic and Clinical Characteristics of Patients

\begin{tabular}{lcc}
\hline \multicolumn{1}{c}{ Variable } & $\begin{array}{c}\text { Mean } \pm \text { SD or } \\
\text { frequency (\%) }\end{array}$ & Range \\
\hline Age (yr) & $53.7 \pm 6.7$ & $36-66$ \\
Gender & & \\
$\quad$ Male & $26(74 \%)$ & \\
Female & $9(26 \%)$ & \\
Height (cm) & $165.0 \pm 7.9$ & $150-180$ \\
Weight (kg) & $66.3 \pm 11.0$ & $40-93$ \\
Operation time (min) & $405.8 \pm 77.5$ & $295-595$ \\
Anesthesia time (min) & $493.0 \pm 77.7$ & $350-685$ \\
Location & & \\
$\quad$ Right & $27(77 \%)$ & \\
$\quad$ Left & $8(23 \%)$ & \\
Crystalloids (ml) & $4,557.4 \pm 1,696.5$ & $2,400-9,900$ \\
Colloids (ml) & $1,291.2 \pm 641.4$ & $100-2,300$ \\
Whole blood, autologous (ml) & $574.6 \pm 300.3$ & $0-1,184$ \\
Packed red blood cell (unit) & $3.3 \pm 2.1$ & $0-9$ \\
Fresh frozen plasma (unit) & $5.2 \pm 2.7$ & $0-10$ \\
Platelet concentrate (unit) & $5.5 \pm 3.0$ & $0-12$ \\
Urine output (ml) & $753.3 \pm 588.7$ & $150-2,670$ \\
Estimated blood loss (ml) & $2,013.2 \pm 1,328.4$ & $500-6,000$ \\
\hline
\end{tabular}

for PICCP when compared with CICCP. Repeated Measures Analysis of Variance (ANOVA) was performed to study whether there were significant differences between PICCP and CICCP using a mixed effects model while accounting for the within-subject variation. Differences were regarded as being statistically significant when $P$ values were less than 0.05 . All statistical analyses were performed by SAS, version 9.1.3 (Cary, NC, USA) and graphical presentations were performed using Stata, version 11.0 (StataCorp, College Station, Texas, USA).

\section{Results}

Demographic and clinical characteristics of the study patients are presented in Table 1. A total of 1342 PICCP/CICCP data pairs were collected from 35 patients and statistically analyzed. For each patient, paired PICCP/CICCP measurements were taken at different time points ( $31-55$ time points). Data on one patient (40 data pairs) were discarded before data analysis due to an inadequate positioning of the PICC tip in the right internal jugular vein.

Table 2 presents the means and standard deviations of PICCP and CICCP at the main surgical periods, along with the estimated bias and 95\% CI of bias. Overall, the measured PICCP was slightly higher than CICCP by $0.14 \mathrm{mmHg}$, but these differences were not statistically different (mean \pm standard deviation for CICCP and PICCP were $7.98 \pm 3.90 \mathrm{mmHg}$ and $8.12 \pm 3.93 \mathrm{mmHg}$, respectively, $\mathrm{P}=0.1435$ ) and bias was well within the limit of agreement. When examining each surgical period, PICCPs were significantly higher than CICCPs during preanhepatic and anhepatic period, but similar during the reperfusion and neohepatic periods. These differences were well within the limit of agreement (Table 2).

Furthermore, Pearson's correlation analysis revealed that PICCP and CICCP were very highly correlated overall $(r=0.970$, $\mathrm{P}<0.001$ ) (Fig. 1). Similarly, a significantly high correlation was observed for data pairs of PICCP and CICCP in patients during each surgical period: preanhepatic (Pearson's correlation coefficient, $\mathrm{r}=0.963, \mathrm{P}<0.001)$, anhepatic $(\mathrm{r}=0.959, \mathrm{P}<0.001)$,

Table 2. PICCP and CICCP during Liver Transplant Surgery

\begin{tabular}{|c|c|c|c|c|c|c|}
\hline Period of LT & $\begin{array}{l}\text { PICCP } \\
(\mathrm{mmHg})\end{array}$ & $\begin{array}{l}\text { CICCP } \\
(\mathrm{mmHg})\end{array}$ & $\begin{array}{c}\text { Bias } \\
(\mathrm{mmHg})\end{array}$ & $P$ value & $\begin{array}{c}\text { 95\% CI of bias } \\
\text { (mmHg) }\end{array}$ & $\begin{array}{c}\text { Limit of agreement } \\
(\mathrm{mmHg})\end{array}$ \\
\hline Total $(n=1342)$ & $8.12 \pm 3.93$ & $7.98 \pm 3.90$ & $0.14 \pm 0.96$ & 0.1435 & 0.09 to 0.19 & -1.74 to 2.02 \\
\hline Preanhepatic $(n=403)$ & $7.88 \pm 4.03$ & $7.55 \pm 3.86$ & $0.33 \pm 1.08$ & 0.0081 & 0.22 to 0.43 & -1.80 to 2.45 \\
\hline Anhepatic $(n=371)$ & $6.71 \pm 3.25$ & $6.38 \pm 3.22$ & $0.32 \pm 0.93$ & $<0.0001$ & 0.23 to 0.42 & -1.50 to 2.14 \\
\hline Reperfusion $(\mathrm{n}=184)$ & $9.80 \pm 3.34$ & $9.95 \pm 3.44$ & $-0.15 \pm 0.82$ & 0.1459 & -0.27 to -0.03 & -1.75 to 1.46 \\
\hline Neohepatic $(n=384)$ & $8.94 \pm 4.18$ & $9.03 \pm 4.04$ & $-0.10 \pm 0.81$ & 0.3168 & -0.18 to -0.02 & -1.69 to 1.50 \\
\hline
\end{tabular}

Values are expressed as means \pm SD or ranges. CICCP: centrally inserted central catheter pressure, PICCP: peripherally inserted central catheter pressure, LT: liver transplantation, Bias: mean difference (PICCP-CICCP), P value: obtained from a mixed effects model for repeated measures analysis by accounting for within-subject variability, $95 \% \mathrm{CI}$ (confidence interval): bias $\pm 1.96 \times$ standard error (SE), Limit of agreement: bias \pm $1.96 \times$ standard deviation (SD). 


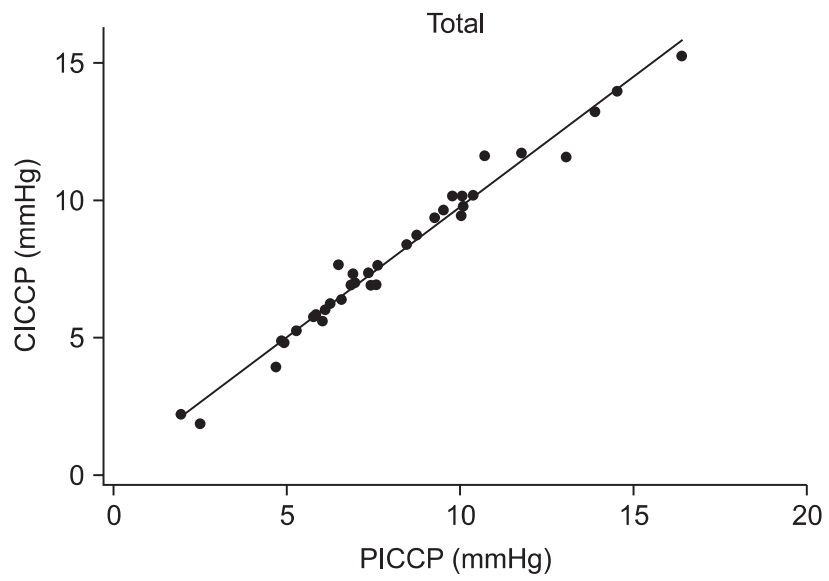

Fig. 1. Linear regression analysis plot of PICCP and CICCP for all data pairs with Pearson's correlation coefficient $(r=0.970, \mathrm{P}<$ 0.001). CICCP: centrally inserted central catheter pressure, PICCP: peripherally inserted central catheter pressure.

A
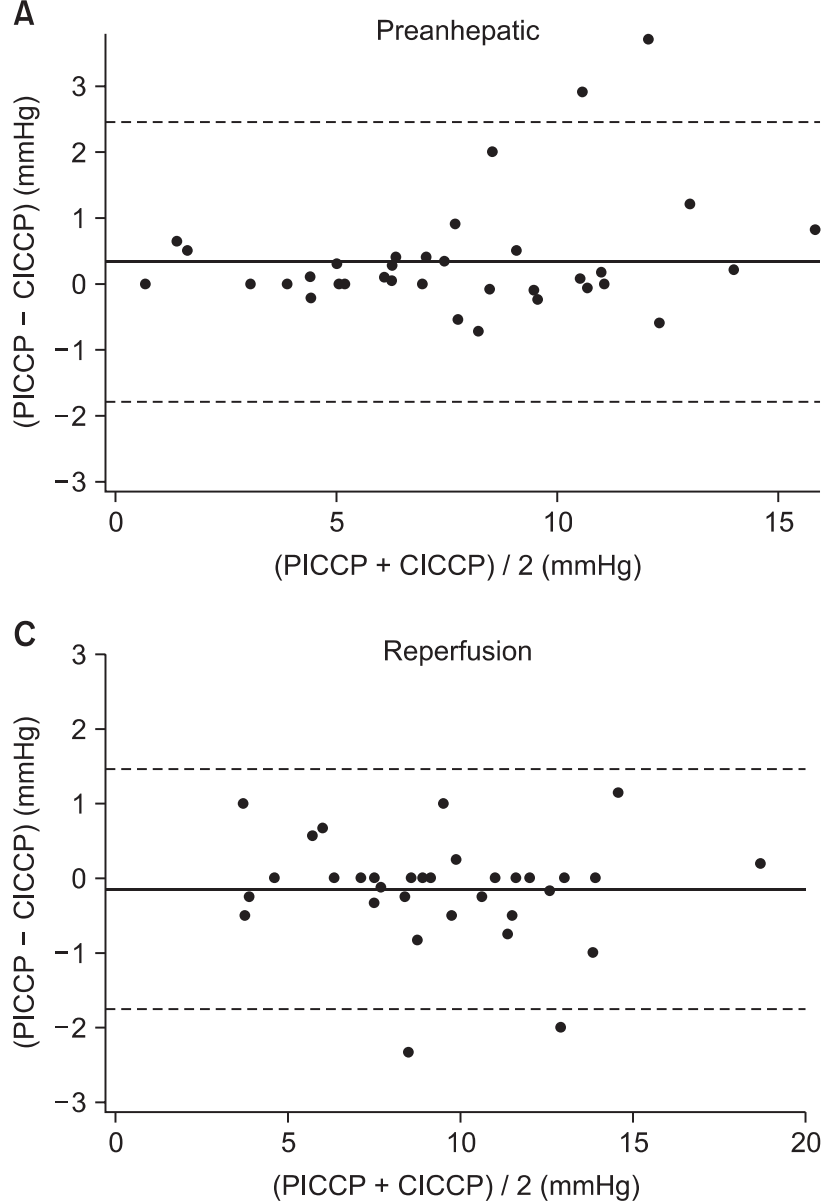

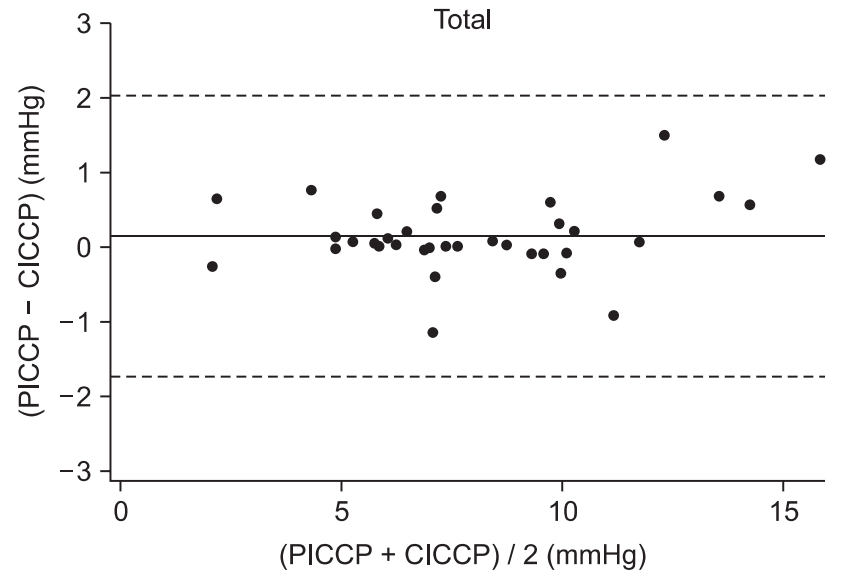

Fig. 2. Bland-Altman plot for all data pairs with calculation of bias and precision. The solid horizontal line represents the mean bias between the two devices. The two dashed horizontal lines represent the mean bias \pm 1.96 times the standard deviation of the differences. CICCP: centrally inserted central catheter pressure, PICCP: peripherally inserted central catheter pressure.
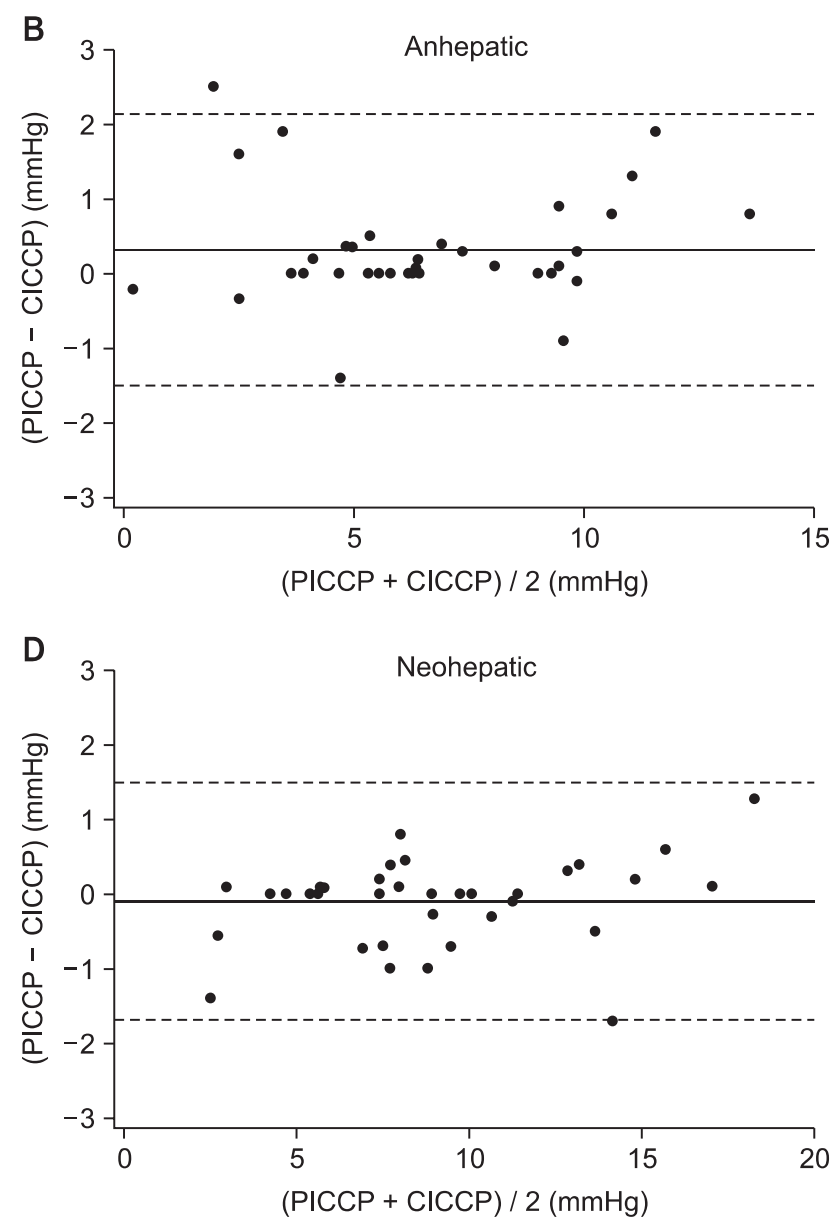

Fig. 3. Bland-Altman plot for each surgical period with calculation of bias and precision. (A) Bland-Altman plot for data points collected during preanhepatic period. (B) Bland-Altman plot for data points collected during anhepatic period. (C) Bland-Altman plot for data points collected during reperfusion period. (D) Bland-Altman plot for data points collected during neohepatic period. The solid horizontal line represents the mean bias between the two devices. The two dashed horizontal lines represent the mean bias \pm 1.96 times the standard deviation of the differences. CICCP: centrally inserted central catheter pressure, PICCP: peripherally inserted central catheter pressure. 
reperfusion $(\mathrm{r}=0.971, \mathrm{P}=0.016)$ and neohepatic $(\mathrm{r}=0.981$, $\mathrm{P}=0.021$ ). Bland-Altman plots also demonstrated very good agreement between the two measurements (Fig. 2 and 3). A total of $96.2 \%$ of all measurements were clinically within the acceptable limits of bias $( \pm 2 \mathrm{mmHg})$.

\section{Discussion}

In this study, PICCP changed in parallel with CICCP with a strong correlation overall and the correlations also remained strong at each surgical period. The overall differences, or bias, between the two measurement devices in this study was $0.14 \mathrm{mmHg}$ (95\% CI of $0.09-0.19 \mathrm{mmHg}$ ), suggesting that the PICCP readings tended to be from 0.09 to $0.19 \mathrm{mmHg}$ higher as determined by Bland-Altman analysis. At each surgical period, the bias remained within $0.33 \mathrm{mmHg}$ at its maximum. Therefore, PICCP can readily represent CVP during hemodynamicly variable situations like LT.

It is difficult to assess the relationship between PICCP and CICCP because a PICC and a CICC are seldom inserted concomitantly in one patient. Therefore, there have been few studies in which simultaneous monitoring of PICCP and CICCP was possible. In our hospital, because a PICC is concomitantly inserted with a CICC at anesthetic induction, both PICCP and CICCP can be measured in one patient during the operation.

Based on a bench study by Black et al. [10] when a PICC is connected to a constant infusion device, PICCP was higher than CICCP by 3 to $4 \mathrm{mmHg}$. However, when performed in patients in the intensive care unit, PICCP was greater than CICCP by only $1 \mathrm{mmHg}$ after 77 data pairs were analyzed [10]. The authors suggested that that warmer in vivo temperature might play a role in this discrepancy between the laboratory data and the clinical data. According to Poiseuille's law, which states $P$ (pressure drop) $=8 \eta \mathrm{lV} /(\pi \mathrm{r} 4 \mathrm{t})$, where $\eta$ is the viscosity coefficient, $\mathrm{l}$ is the length, $\mathrm{V} / \mathrm{t}$ is the flow, and $\mathrm{r}$ is the radius [14], the expanded lumen and lowered viscosity by a higher in vivo temperature can possibly result in a lower pressure drop and small pressure differences. Unlike the previous study in nonsurgical patients [10], our study was performed in the surgical patients with widely fluctuating hemodynamic variables due to the manipulation of relatively large vessels. However, our results showed an even smaller difference between CICCP and PICCP than those in the aforementioned and this was probably due to the acquired stability from a larger number of data pairs.

Recently, some authors reported that the transduction of peripheral venous pressure might replace the measurement of CVP [15-17]. However, there are some limitations monitoring CVP from peripheral venous pressure. CVP can be measured from a peripheral intravenous catheter only when there is continuity with the central venous compartment, demonstrated by an increase in the CVP from the peripheral intravenous catheter in response to a sustained inspiratory effort and by occlusion of the extremity above the site of the catheter [18]. Moreover, a peripheral venous pressure measurement does not accurately estimate the absolute value of CVP in critically ill patients [19].

During LT, hemodynamic instability is characteristic due to cross-clamping of the inferior vena cava, sudden massive bleeding and reperfusion of the donor graft during the procedure [12]. One of the major objectives of our study was to observe the influence of the acute hemodynamic changes on the PICCP-CICCP differences. Overall, a dramatic change in systemic hemodynamic conditions during LT was not associated with significant differences in PICCP and CICCP in our study. Based on the statistical analysis using the repeated measures ANOVA comparing the bias of the four surgical periods, bias during the neohepatic period $(-0.10 \mathrm{mmHg})$ was not statistically different from the reperfusion period $(-0.15 \mathrm{mmHg})$, but different from those of the preanhepatic $(0.33 \mathrm{mmHg})$ and anhepatic $(0.32 \mathrm{mmHg})$ periods. However, all differences were at most $0.33 \mathrm{mmHg}$ which is likely to be clinically negligible. PICCP-CICCP differences were statistically significant during the preanhepatic and anhepatic periods by $0.33 \mathrm{mmHg}$ and $0.32 \mathrm{mmHg}$, respectively and PICCP showed strong correlations with CICCP during these two periods ( $\mathrm{r}=0.963$ and 0.959 , respectively). These findings suggest that during the preanhepatic and anhepatic periods, PICCP was parallel with CICCP and was consistently higher than the CICCP by about $0.3 \mathrm{mmHg}$. During the reperfusion and neohepatic periods, differences between the PICCP and the CICCP were not statistically and clinically significant $(-0.15 \mathrm{mmHg}$ and $-0.10 \mathrm{mmHg}$, respectively) while the correlations remained strong $(\mathrm{r}=0.971,0.981$ respectively). There is practically no difference between PICCP and CICCP during the reperfusion and neohepatic periods.

The expected relationship in which the PICCP was a few mmHg higher than CICCP described in the previous study [10] was actually reversed, with the CICCP marginally higher than PICCP in the reperfusion and neohepatic periods in our study. According to Poiseuille's law $(\mathrm{P}=8 \eta \mathrm{lV} /(\pi \mathrm{r} 4 \mathrm{t}))$, the components of the resistance in the PICC are length, diameter of lumen, flow rate and viscosity. The viscosity becomes higher with higher hemoglobin levels and lower temperatures. In our study, CVP was measured from the CVP port on the PAC inserted through the AVA catheter. In the reperfusion period, a large amount of blood products are infused rapidly through the AVA catheter, increasing the viscosity and the flow rate resulting in higher pressure drops according to Poiseuille's law. Therefore, it is suggested that the CVP reading could become higher and consequently the PICCP-CICCP differences can become 
smaller during this period. This is the theoretical explanation with Poiseuille's law and is based on the assumption that the laminar flow exists across the length of a catheter in a closed system and the effects of surface tension are equal throughout the length of the catheter.

Characteristic CVP waveforms (a-, c-, and v-wave excursions) can be helpful in the diagnosis of arrhythmia, tricuspid valve disease, pericardial disease, and right ventricular dysfunction [16]. In one study which compared the waveforms of the CICCP and PICCP [20] (although there was some phase delay in the PICC waveform), the peaks, troughs and means of the dynamic pressure waveforms of the $5 \mathrm{Fr}$ and 6 Fr PICC were equal to those of the 7 Fr triple lumen conventional CICC control. Therefore, PICCP waveforms also can be helpful to analyze various cardiovascular conditions, similar to the CICCP.

PICCs have been in use primarily to provide longterm venous access necessary for parenteral nutrition and chemotherapy [21]. PICC also can be used instead of the CICC for CVP measurement in the variety of situations where typical approaches with central catheters are not feasible. It would be also advantageous to use CVP information available in patients already with PICCs without performing additional invasive procedures. In consideration of our findings, PICCP would reflect CICCP even more reliably if flow rate and viscosity are maintained stable by appropriate infusion methods and temperature management. Our study was performed in PICCs newly cannulated in the operating theatre and the measurement was done with relatively large bore catheters with the arm abducted at 90 degrees. Hands held in parallel to the body (like in maxillofacial/neck surgeries) might cause kinks at the clavicle area. Also, in children, the catheter is much smaller and therefore damping might ensue.

Although PICC can reduce the acute risk of pneumothorax and inadvertent arterial puncture, clinicians should consider the possibility of other complications such as catheter malposition, thrombosis, phlebitis and cardiac tamponade associated with the PICC $[22,23]$. Therefore, when positioning the PICC tip, it is vital to allow for movement of the catheter that will occur with arm abduction and to check chest radiography to confirm the location of the catheter tip [23].

In conclusion, our study confirmed that the PICCP and the CICCP correlate well under conditions associated with LT surgery. A high level of agreement found in this study and the PICCP may therefore represent an attractive alternative to CICCP monitoring in other patient populations with similar intraoperative hemodynamic derangements.

\section{References}

1. Cheung AT, Savino JS, Weiss SJ, Aukburg SJ, Berlin JA. Echocardio- graphic and hemodynamic indexes of left ventricular preload in patients with normal and abnormal ventricular function. Anesthesiology 1994; 81: 376-87.

2. Magder S. Central venous pressure monitoring. Curr Opin Crit Care 2006; 12: 219-27.

3. Unnikrishnan D, Idris N, Varshneya N. Complete heart block during central venous catheter placement in a patient with pre-existing left bundle branch block. Br J Anaesth 2003; 91: 747-9.

4. Domino KB, Bowdle TA, Posner KL, Spitellie PH, Lee LA, Cheney FW. Injuries and liability related to central vascular catheters: A closed claims analysis. Anesthesiology 2004; 100: 1411-8.

5. Jeganath V, McElwaine JG, Stewart P. Ruptured superior thyroid artery from central vein cannulation: Treatment by coil embolization. Br J Anaesth 2001; 87: 302-5.

6. Jankovic Z, Boon A, Prasad R. Fatal haemothorax following largebore percutaneous cannulation before liver transplantation. $\mathrm{Br} J$ Anaesth 2005; 95: 472-6.

7. Fangio P, Mourgeon E, Romelaer A, Goarin JP, Coriat P, Rouby JJ. Aortic injury and cardiac tamponade as a complication of subclavian venous catheterization. Anesthesiology 2002; 96: 1520-2.

8. Monteiro AJ, Canale LS, Barbosa R, Meier M. Cardiac tamponade caused by central venous catheter in two newborns. Rev Bras Cir Cardiovasc 2008; 23: 422-4.

9. Ng PK, Ault MJ, Maldonado LS. Peripherally inserted central catheters in the intensive care unit. J Intensive Care Med 1996; 11: 49-54.

10. Black IH, Blosser SA, Murray WB. Central venous pressure measurements: Peripherally inserted catheters versus centrally inserted catheters. Crit Care Med 2000; 28: 3833-6.

11. McLemore EC, Tessier DJ, Rady MY, Larson JS, Mueller JT, Stone $\mathrm{WM}$, et al. Intraoperative peripherally inserted central venous catheter central venous pressure monitoring in abdominal aortic aneurysm reconstruction. Ann Vasc Surg 2006; 20: 577-81.

12. Estrin JA, Belani KG, Ascher NL, Lura D, Payne W, Najarian JS. Hemodynamic changes on clamping and unclamping of major vessels during liver transplantation. Transplant Proc 1989; 21: 3500-5.

13. Bland JM, Altman DG. Statistical methods for assessing agreement between two methods of clinical measurement. Lancet 1986; 1: 307-10.

14. Pfitzner J. Poiseuille and his law. Anaesthesia 1976; 31: 273-5.

15. Hoftman N, Braunfeld M, Hoftman G, Mahajan A. Peripheral venous pressure as a predictor of central venous pressure during orthotopic liver transplantation. J Clin Anesth 2006; 18: 251-5.

16. Desjardins R, Denault AY, Belisle S, Carrier M, Babin D, Levesque $\mathrm{S}$, et al. Can peripheral venous pressure be interchangeable with central venous pressure in patients undergoing cardiac surgery? Intensive Care Med 2004; 30: 627-32.

17. Amar D, Melendez JA, Zhang H, Dobres C, Leung DH, Padilla RE. Correlation of peripheral venous pressure and central venous pressure in surgical patients. J Cardiothorac Vasc Anesth 2001; 15: 40-3.

18. Tobias JD, Johnson JO. Measurement of central venous pressure from a peripheral vein in infants and children. Pediatr Emerg Care 2003; 19: 428-30.

19. Charalambous C, Barker TA, Zipitis CS, Siddique I, Swindell R, Jackson R, et al. Comparison of peripheral and central venous pressures in critically Ill patients. Anaesth Intensive Care 2003; 31: 
34-9.

20. Latham HE, Dwyer TT, Gregg BL, Simpson SQ. An in vitro study comparing a peripherally inserted central catheter to a conventional central venous catheter: no difference in static and dynamic pressure transmission. BMC Anesthesiol 2010; 10: 18-24.

21. Molloy D, Smith LN, Aitchison T. Cytotoxic chemotherapy for incurable colorectal cancer: Living with a picc-line. J Clin Nurs 2008; $17: 2398-407$.
22. Turcotte S, Dubé S, Beauchamp G. Peripherally inserted central venous catheters are not superior to central venous catheters in the acute care of surgical patients on the ward. World J Surg 2006; 30: 1605-19.

23. Orme RM, McSwiney MM, Chamberlain-Webber RF. Fatal cardiac tamponade as a result of a peripherally inserted central venous catheter: a case report and review of the literature. Br J Anaesth 2007; 99: 384-8. 